\title{
Advanced Lung Cancer-Reaching a Survival Ceiling with Chemotherapy, the Nibs, and the Mabs
}

\author{
Riccardo Lencioni $^{1}$, James Chen ${ }^{2}$, Gordon Downie ${ }^{3}$, Llew Keltner ${ }^{2}$ \\ ${ }^{1}$ Department of Surgery, Pisa University School of Medicine, Pisa, Italy; ${ }^{2}$ Light Sciences Oncology, Inc., Bellevue, USA; ${ }^{3}$ Titus Re- \\ gional Medical Center, Mount Pleasant, USA. \\ Email: lencioni@med.unipi.it
}

Received February $8^{\text {th }}$, 2011; revised March 29 ${ }^{\text {th }}, 2011$; accepted April $7^{\text {th }}, 2011$.

\begin{abstract}
Lung cancer is the leading cause of cancer-related death worldwide. Despite intensive research conducted during the past years, little improvement in overall survival has been achieved for patients with advanced disease. Chemotherapy and radiation continue to be the mainstays of treatment for unresectable patients, and targeted agents seem to have added little improvement to overall survival while dramatically increasing costs and producing significant clinical side effects. In contrast to the immunosuppression which occurs as a result of the use of chemotherapy and pathway blockers, novel therapies are emerging which either stimulate tumor specific immune responses due to apoptotic focal tumor destruction or attack tumor-induced regulatory T-cell immunosuppression. Such new approaches should be fully explored, as they have potential to offer very different outcomes for advanced lung cancer patients.
\end{abstract}

Keywords: Lung Cancer, Chemotherapy, Targeted Therapy

\section{Introduction}

Lung cancer is the leading cause of cancer-related deaths in the United States and worldwide [1,2]. Intensive research and many clinical trials have yielded little improvement in overall survival (OS), according to the American Cancer Society [3]. A recent study using the SEER database demonstrated that, between the years 1990 and 2005, one-year OS increased from 13.2 to $19.4 \%$, and two-year OS only increased from 4.5 to $7.8 \%$ [4]. For non-small cell lung cancer, the most prevalent type, the one-year survival rate for all stages combined has remained unchanged for many years at approximately $15 \%[2,5]$. The 5 -year survival for patients diagnosed with stage IV disease is only $1 \%$ [6]. Chemotherapy and radiation continue to be the mainstays of treatment for patients with advanced disease, and targeted agents (biologics) seem to have added little improvement to OS while dramatically increasing costs and producing significant clinical side effects.

\section{Chemotherapy}

Guidelines for treatment of stage IV disease (the most advanced patients) have very recently been updated by the American Society of Clinical Oncology [7]. Patients with good performance status are best treated with a platinum-based, two-drug combination, and patients with poor performance status are treated with a single cytotoxic drug. The doublet combinations of platinum compounds include cisplatin or carboplatin with gemcitabine, vinorelbine, pemetrexed, or taxanes [8].

\section{Targeted Drug Therapy}

\subsection{Bevacizumab}

Bevacizumab is an antiangiogenic agent that has undergone three randomized controlled trials (RCT) in combination with chemotherapy. One RCT of carboplatin/paclitaxel with or without bevacizumab showed a very modest improvement in OS of 2 months (from 10.3 to 12.3 months) at the expense of increased toxicity (grade 4 and 5) involving hematologic and nonhematologic systems [7,9]. In elderly patients, no improvement in survival has been demonstrated. The combination of bevacizumab with other cytotoxic regimens has not improved OS and is not recommended [7]. A Phase 3 controlled, double-blinded study of bevacizumab and erlotinib versus erlotinib in a second-line role did not 
demonstrate any enhanced survival (9.3 vs 9.2 months) [6]. The approximate cost of addition of bevacizumab to a chemotherapy regimen is $\$ 90 \mathrm{~K}$ [10]. Based on this added cost and small incremental OS advantage, some opinion leaders have questioned the cost effectiveness of bevacizumab [10].

\subsection{Cetuximab}

Cetuximab is an antibody that binds the epidermal growth factor receptor (EGFR) [2]. Four RCTs have explored chemotherapy with or without cetuximab. One study demonstrated an improvement of 1.2 months in OS (11.3 vs 10.1 months) with the addition of cetuximab along with increased gastrointestinal and dermatologic toxicity [7]. Cetuximab also increases the rate of grade $3 / 4$ febrile neutropenia [11]. The approximate cost of addition of cetuximab to a chemotherapy regimen is $\$ 80 \mathrm{~K}$ [10]. Based on this added cost and small incremental OS advantage, some opinion leaders have questioned the cost effectiveness of cetuximab [10].

\subsection{Erlotinib and Gefitinib}

Erlotinib and gefitinib are reversible EGFR tyrosine kinase inhibitors (TKIs) used primarily as second- or third-line treatment. After prior chemotherapy treatment, erlotinib was shown to be superior to placebo and increased OS by 2 months (6.7 vs 4.7 months) [12]. Gefitinib failed to demonstrate a survival advantage in previously treated patients in another Phase 3 trial [12]. The EGFR TKIs combined with chemotherapy have failed to show any benefit compared with chemotherapy alone in four large RCTs [12]. Another limitation is increased toxicity in elderly patients [11]. However, certain patient characteristics-namely, Asian race, female gender, never smoker status, and adenocarcinoma histologymay confer a survival advantage with EGFR TKIs [12, 13]. The approximate cost of addition of erlotinib to a chemotherapy regimen is $\$ 16,200$ [10]. Based on the added cost and small incremental OS advantage, the National Institute for Clinical Excellence (NICE) in Great Britain has recommended that erlotinib be used in National Health Service patients as an alternative to docetaxel in second-line treatment for lung cancer "only on the basis that it is provided by the manufacturer at an overall treatment cost (including administration, adverse events and monitoring costs) equal to that of docetaxel" [14]. NICE does not recommend erlotinib "as secondline treatment of locally advanced or metastatic NSCLC in patients for whom docetaxel is unsuitable (that is, where there is intolerance of or contraindications to docetaxel) or for third-line treatment after docetaxel therapy.” Other payers may follow NICE's guidance for erlotinib.

\subsection{Other Platinum-Based Combinations and Maintenance Therapy}

A large randomized Phase 3 study has been conducted comparing cisplatin/gemcitabine to cisplatin/pemetrexed; overall survival was 10.3 months in both groups [8]. Due to the perceived efficacy plateau in the first-line setting for advanced disease, the concept and practice of maintenance therapy has been promulgated as a means of enhancing survival [15]. The initiation of maintenance therapy presupposes lack of progressive disease with front-line therapy. Currently, pemetrexed has been demonstrated to afford patients significantly longer progression free survival versus placebo in a maintenance role after platinum-based first-line chemotherapy. Improvement in median OS has yet to be shown [15].

\section{Discussion}

Multiple clinical trials have demonstrated that most of the survival benefit of systemic agents accrues with doublet chemotherapy, which can afford a median OS on the order of 7 to 10 months with significant associated toxicity $[11,12]$. The median survival with palliative measures alone ranges from 2 to 5 months [16]. One third of patients with non-small cell lung cancer do not receive further therapy past the first-line, for a number of reasons [15].

Targeted agents have been largely disappointing in the majority of patients, with the exception of perceived improved survival seen in a small subset of never-smoking, Asian females. However, in a recent Japanese phase III trial NEJ002, and the Iressa Pan-Asia Study (IPASS), no change in overall survival was noted comparing gefitinib to platinum-doublet chemotherapy $[17,18]$.

Despite stagnant survival rate improvements, costs for oncology drugs continue to rise. NICE requires that drugs cost less than $£ 30 \mathrm{~K}(\sim \$ 4 \mathrm{~K}$ currently) per quality adjusted life year in order to be reimbursed. Published studies of targeted agents in NSCLC would seem to fall far short of this goal. For example, a 12-week regimen of bevacizumab, with a 1.2-month increase in survival can be extrapolated to cost $\$ 800 \mathrm{~K}$ to prolong a patient's life by one year [10]. Despite the best efforts of the biotech and pharmaceutical industry, and despite rapidly increasing prices of oncology drugs, survival rates have largely reached a plateau.

Targeted agents in the first and subsequent lines have added significantly to toxicity as well [19]. Due to the tremendous genetic diversity of lung cancer, which confers tumor resistance, development of more "nibs," "mabs," combinations thereof, and other narrow pathway blockers will likely continue to yield little in improved OS while driving treatment costs up significantly $[13,20]$. The ma- 
jority of patients are primarily resistant (initially refractory) or acquire resistance (experience loss of response) to EGFR TKIs and will likely be resistant to other similar agents in development [11]. Moreover, most advanced lung cancer patients are older and many are unfit for the optimal chemotherapy regimens; therefore, other alternative, truly innovative approaches to advanced lung cancer are desperately needed for the disease, which continues to increase in overall incidence worldwide [21].

In contrast to the immunosuppression which occurs as a result of the use of chemotherapies and pathway blockers, [22-24] novel therapies are emerging which either stimulate tumor specific immune responses due to apoptotic focal tumor destruction[25] or attack tumor-induced regulatory T-cell immunosuppression [26].

New approaches should be funded and explored, including ablative and non-ablative focal therapy which may offer very different outcomes for advanced lung cancer patients with potential for fewer side effects.

\section{Acknowledgements}

The authors take full responsibility for the scope, direction and content of the manuscript. They would like to thank Research Analysis Library for the assistance in the literature review and in the preparation of the draft manuscript. Editorial assistance was supported by Light Science Oncology, Inc.

\section{REFERENCES}

[1] G. D’Addario, D. Rauch, R. Stupp, M. Pless, R. Stahel, N. Mach, L. Jost, L. Widmer, C. Tapia, M. Bihl, M. Mayer, K. Ribi, S. Lerch, L. Bubendorf and D. C. Betticher, "Multicenter Phase II Trial of Gefitinib First-Line Therapy Followed by Chemotherapy in Advanced NonSmall-Cell Lung Cancer (NSCLC): SAKK Protocol 19/03," Annals of Oncology, Vol. 19, No. 4, 2008, pp. 739-745. doi:10.1093/annonc/mdm564

[2] S. Huq, I. Maghfoor and M. Perry, "Lung Cancer, Non-Small Cell,” Medscape.com, 2009. http://emedicine. medscape.com/article/279960-print.)

[3] S. Reinberg, “More Dollars Don’T Boost Lung Cancer Survival,” 2007.

http:/health.usnews.com/usnews/health/healtday/071023/ more-dollars-dont-boost-lung-cancer-survival.htm.)

[4] D. Morgensztern, S. Waqar, J. Subramanian, F. Gao and R. Govindan, "Improving Survival for Stage IV Non-Small Cell Lung Cancer: A Surveillance, Epidemiology, and End Results Survey from 1990 to 2005,” Journal of Thoracic Oncology, Vol. 4, No. 12, 2009, pp. 1524-1529. doi:10.1097/JTO.0b013e3181ba3634

[5] K. L. Reckamp, B. K. Gardner, R. A. Figlin, D. Elashoff, K. Krysan, M. Dohadwala, J. Mao, S. Sharma, L. Inge, A. Rajasekaran and S. M. Dubinett, "Tumor Response to Combination Celecoxib and Erlotinib Therapy in NonSmall Cell Lung Cancer is Associated with a Low Base- line Matrix Metalloproteinase-9 and a Decline in Serum-Soluble E-cadherin,” Journal of Thoracic Oncology, Vol. 3, No. 2, 2008, pp. 117-124. doi:10.1097/JTO.0b013e3181622bef

[6] E. A. Kotteas, A. G. Charpidou and K. N. Syrigos, "Targeted Therapy for Nonsmall Cell Lung Cancer: Focusing on Angiogenesis, the Epidermal Growth Factor Receptor and Multikinase Inhibitors,” Anticancer Drugs, Vol. 21, No. 2, 2010, pp. 151-168.

doi:10.1097/CAD.0b013e328334da02

[7] C. G. Azzoli, S. Baker Jr., S. Temin, W. Pao, T. Aliff, J. Brahmer, D. H. Johnson, J. L. Laskin, G. Masters, D. Milton, L. Nordquist, D. G. Pfister, S. Piantadosi, J. H. Schiller, R. Smith, T. J. Smith, J. R. Strawn, D. Trent and G. Giaccone, "American Society of Clinical Oncology Clinical Practice Guideline Update on Chemotherapy for Stage IV Non-Small-Cell Lung Cancer,” Journal of Clinical Oncology, Vol. 27, No. 36, 2009, pp. 6251-6266. doi:10.1200/JCO.2009.23.5622

[8] G. V. Scagliotti, P. Parikh, J. von Pawel, B. Biesma, J. Vansteenkiste, C. Manegold, P. Serwatowski, U. Gatzemeier, R. Digumarti, M. Zukin, J. S. Lee, A. Mellemgaard, K. Park, S. Patil, J. Rolski, T. Goksel, F. de Marinis, L. Simms, K. P. Sugarman and D. Gandara, "Phase III Study Comparing Cisplatin Plus Gemcitabine with Cisplatin Plus Pemetrexed in Chemotherapy-Naive Patients with Advanced-Stage Non-Small-Cell Lung Cancer,” Journal of Clinical Oncology, Vol. 26, No. 21, 2008, pp. 3543-3551. doi:10.1200/JCO.2007.15.0375

[9] A. Sandler, "Bevacizumab in Non Small Cell Lung Cancer,” Clinical Cancer Research, Vol. 13, No. 15, 2007, pp. s4613-4616. doi:10.1158/1078-0432.CCR-07-0647

[10] T. Fojo and C. Grady, "How Much is Life Worth: Cetuximab, Non-Small Cell Lung Cancer, and the \$440 Billion Question,” Journal of the National Cancer Institute, Vol. 101, No. 15, 2009, pp. 1044-1048. doi:10.1093/jnci/djp177

[11] H. A. Burris, "Shortcomings of Current Therapies for Non-Small-Cell Lung Cancer: Unmet Medical Needs," Oncogene, Vol. 28, No. 1 (Supplement), 2009, pp. S4-13. doi:10.1038/onc.2009.196

[12] T. Fong, D. Morgensztern and R. Govindan, "EGFR Inhibitors as First-Line Therapy in Advanced Non-Small Cell Lung Cancer,” Journal of Thoracic Oncology, Vol. 3, No. 3, 2008, pp. 303-310. doi:10.1097/JTO.0b013e3181645477

[13] L. Horn and A. Sandler, "Epidermal Growth Factor Receptor Inhibitors and Antiangiogenic Agents for the Treatment of Non-Small Cell Lung Cancer," Clinical Cancer Research, Vol. 15, No. 16, 2009, pp. 5040-5048. doi:10.1158/1078-0432.CCR-09-0520

[14] National Institute for Health and Clinical Excellence, "NICE Technology Appraisal Guidance 162, Erlotinib for the Treatment of Non-Small-Cell Lung Cancer,” 2010. http://www.nice.org.uk/TA162.

[15] T. S. Mok and S. S. Ramalingam, "Maintenance Therapy in Nonsmall-Cell Lung Cancer: A New Treatment Paradigm,” Cancer, Vol. 115, No. 22, 2009, pp. 5143-5154. 


\section{doi:10.1002/cncr.24563}

[16] M. S. Reif and M. P. Rivera, "Evidence-Based Outcomes for Patients with Advanced Non-Small Cell Lung Cancer," Seminars in Respiratory and Critical Care Medicine, Vol. 21, No. 1, 2000, pp. 443-449. doi:10.1055/s-2000-9405

[17] K. Suda, K. Tomizawa and T. Mitsudomi, "Biological and Clinical Significance of KRAS Mutations in Lung Cancer: An Oncogenic Driver that Contrasts with EGFR Mutation," Cancer and Metastasis Reviews, Vol. 29, No. 1, 2010, pp. 49-60. doi:10.1007/s10555-010-9209-4

[18] B. Boughton, "Two Clinical Trials on Gefitinib Show Benefits for Asian Lung Cancer Patients,” Medscape.com, 2009.http://www.medscape.com/viewarticle/707751_prin t.)

[19] S. M. Gadgeel, "Targeted Therapy in Lung Cancer: The Good, the Bad, and the Ugly,” Clinical Lung Cancer, Vol. 10, No. 1, 2009, pp. 10-12. doi:10.3816/CLC.2009.n.002

[20] E. D. Pleasance, P. J. Stephens, S. O’Meara, D. J. McBride, A. Meynert, D. Jones, M. L. Lin, D. Beare, K. W. Lau, C. Greenman, I. Varela, S. Nik-Zainal, H. R. Davies, G. R. Ordonez, L. J. Mudie, C. Latimer, S. Edkins, L. Stebbings, L. Chen, M. Jia, C. Leroy, J. Marshall, A. Menzies, A. Butler, J. W. Teague, J. Mangion, Y. A. Sun, S. F. McLaughlin, H. E. Peckham, E. F. Tsung, G. L. Costa, C. C. Lee, J. D. Minna, A. Gazdar, E. Birney, M. D. Rhodes, K. J. McKernan, M. R. Stratton, P. A. Futreal and P. J. Campbell, “A Small-Cell Lung Cancer Genome with Complex Signatures of Tobacco Exposure,” Nature, Vol. 463, No. 7228, 2010, pp. 184-190. doi:10.1038/nature08629

[21] C. Gridelli, P. Maione, A. Rossi, G. Palazzolo, G. Colantuoni and E. Rossi, "Management of Unfit Older Patients with Advanced NSCLC," Cancer Treatment Reviews,
Vol. 35, No. 6, 2009, pp. 517-521. doi:10.1016/j.ctrv.2009.04.011

[22] L. A. Emens, J. P. Machiels, R. T. Reilly and E. M. Jaffee, "Chemotherapy: Friend or Foe to Cancer Vaccines?" Current Opinion in Molecular Therapeutics, Vol. 3, No. 1, 2001, pp. 77-84.

[23] M. Krusch, J. Salih, M. Schlicke, T. Baessler, K. M. Kampa, F. Mayer and H. R. Salih, "The Kinase Inhibitors Sunitinib and Sorafenib Differentially Affect NK Cell Antitumor Reactivity in Vitro," The Journal of Immunology, Vol. 183, No. 12, 2009, pp. 8286-8294. doi:10.4049/jimmunol.0902404

[24] K. R. Molhoek, C. C. McSkimming, W. C. Olson, D. L. Brautigan and C. L. Slingluff Jr., "Apoptosis of CD4(+) CD25(high) T Cells in Response to Sirolimus Requires Activation of T Cell Receptor and is Modulated by IL-2," Cancer Immunology Immunotherapy, Vol. 58, No. 6, 2009, pp. 867-876. doi:10.1007/s00262-008-0602-6

[25] E. Bromley, B. Owczarczak, L. Keltner, S. Wang and S. O. Gollnick, "Characterization of an Anti-Tumor Immune Response after Light-Activated Drug Therapy Using Talaporfin Sodium in a Spontaneously Metastasizing Mammary Tumor Model,” Journal of Clinical Oncology, Vol. 27, No. 15s, 2009, p. 3052.

[26] J. D. Wolchok, B. Neyns, G. Linette, S. Negrier, J. Lutzky, L. Thomas, W. Waterfield, D. Schadendorf, M. Smylie, T. Jr. Guthrie, J. J. Grob, J. Chesney, K. Chin, K. Chen, A. Hoos, S. J. O’Day and C. Lebbe, "Ipilimumab Monotherapy in Patients with Pretreated Advanced Melanoma: A Randomised, Double-Blind, Multicentre, Phase 2, Dose-Ranging Study," The Lancet Oncology, Vol. 11, No. 2, 2010, pp. 155-164. doi:10.1016/S1470-2045(09)70334-1 